\title{
Crossing the Bridge from the Education Campus Island to the Community: Will we Walk or do we Learn to Swim?
}

\author{
Paul Worley ${ }^{1}$
}

Published online: 20 October 2015

(C) International Association of Medical Science Educators 2015

In this thesis, I argue that an emerging alignment of disruptive pedagogies and technologies may change the face of medical education, including the learning of basic medical sciences, and call into question the future role and relevance of current staff, structures and institutional venues.

\section{The Disruptive Pedagogies of Social Accountability-the Power of the Local}

As we move through the second decade of the twenty-first century, health professional education is increasingly being evaluated through a social accountability lens [1]. The WHO defines social accountability in medical education as "the obligation to orient education, research, and service activities towards priority health concerns of the local communities, the region and/or nation one has a mandate to serve. These priorities are jointly defined by government, health service organisations, and the public" [2].

This lens is evident in position statements by organisations such as the Training for Health Equity Network (THEnet) [3], the World Federation for Medical Education [4], and the Global Consensus on Social Accountability in Medical Education [5], and by the Association for Medical Education in Europe including social accountability as one of only three categories for their awards for excellence in medical education (the ASPIRE initiative [6]).

Paul Worley

paul.worley@flinders.edu.au

1 School of Medicine, Flinders University, Adelaide, South Australia, Australia
As an example, I see social accountability being played out in our school through a team of paediatric medical scientists and clinicians who are educating our MD students in an environment bathed by research that is impacting our community, in this case, a group focused on discovering and implementing new approaches to the basic scientific understanding and treatment of bronchiolitis, the most common reason in our community for infants to be separated from their homes and families. These scientists and clinicians are inspirational mentors to MD students eager to adopt positive role models.

In clinical education, this social accountability lens has resulted in a sometimes radical shift of clinical teaching out of the traditional single tertiary hospital campus and into multiple community settings, particularly in underserved regions $[7,8]$. This has been supported by the disruptive technology of longitudinal integrated clerkships (LICs), a relationship-based pedagogy where medical students undertake an entire academic year of clinical study based in community settings, often with an emphasis on primary care teachers, rather than undertaking tertiary hospital rotations through the traditional specialist disciplines [9]. Many medical schools base LICs in multiple dispersed sites and use blended eLearning approaches to assist students to be able to access core learning materials and library resources.

Schools have developed LICs based in underserved communities because of the known association with an increased likelihood that graduates of these programs will choose careers based in these community settings [10, 11]. Additional research has demonstrated that the academic results [12] achieved by students in these settings are at least equivalent to their traditional campus peers and, in the areas of professionalism, there appear to be significant additional benefits [13].

With some notable exceptions [14, 15], however, the basic science teaching in health profession courses has remained 
behind the closed doors of academic centres. Although integrative teaching methods such as problem-based learning (PBL) and systems-based learning may have changed the names of the topics students are required to undertake, the teachers, research active scientists, and the venue of learning, the central university campus and hospital, have remained similar to those involved 100 years ago. A focus on bench to bedside research has reinforced this co-location, but has also resulted in a great difficulty in moving research findings out of university tertiary hospitals and into broader community-based clinical practice-the so-called T2 implementation gap [16].

\section{The Disruptive Technologies of the Democratisation of Knowledge-the Power of the Global}

In the twenty-first century, in parallel with this disciplined stability in medical science education, there has been an uncontrolled explosion of knowledge and access to knowledge through the Internet. Medical science knowledge is no longer owned uniquely by the university sector [17]. The formal curriculum is no longer the unique repository, as it is accompanied by a vast array of lectures, articles, simulations and explanations available freely to any who choose, including, but not limited to, those students who have paid for their formal resources [18].

In clinical education, this revolution has been embraced by education reformers, providing a common bedrock of knowledge and tuition to students who may be dispersed over a variety of different sites and who, by nature of the unpredictability of clinical presentations, all have unavoidably different gaps in the way their clinical learning experiences cover the required broad clinical curriculum. This has supported 'just in time' learning and encouraged students to spend more time with patients in formal clinical environments rather than sitting in sequestered libraries [19].

A different picture emerges in relation to the basic medical sciences. Unless required by course rules, attendance at formal curriculum sessions is falling as students are constructing their own approaches to learning the required material, with timetables and venues that suit the other commitments in their lives. Students are developing a parallel curriculum and set of learning resources [20], sometimes involving global collaborations.

In our school, teachers used to performing in front of large classes are becoming demoralised as they front the couple of dozen students who have chosen to attend. Even these students often appear to spend most of the lecture engrossed in their own screens rather than the academic presentation.

There is therefore a dichotomy developing in medical education.

In clinical education, innovators have embraced the opportunities provided by the digital world to develop new pedagogies that enable students to learn in an expanded variety of settings and a new cadre of teachers that are relevant to community needs. Students and faculty have embraced this with renewed enthusiasm.

In medical science education, despite innovation in teaching methods, there has been what appears to be inertia in regards to both settings and teachers, with criticism of students' poor attitudes as they vote with their feet and learn in new venues from teachers they choose to access from across the world.

Social accountability, with a shift to community-based learning, has been a driving force behind the twenty-first century transformation in clinical education. Could it likewise be a successful stencil for the medical sciences?

\section{Innovations and Implications}

Three examples may illustrate potential ways forward, each with evidence of excellent academic outcomes, enthusiastic student engagement, and positive community support.

In the USA, the University of New Mexico established a parallel track for up to 20 medical students who undertook 4 months of their second year based in small rural communities [21]. In Canada, the Northern Ontario School of Medicine requires students in small groups of 2-4 to undertake 4 weeks of Year 1 based in a small rural community and 4 weeks of Year 2 based in a Native American community, whilst still continuing their regular basic science learning $[22,23]$. And in Australia, Flinders University now delivers their entire MD program for a group of 24 students based $3000 \mathrm{~km}$ from the Adelaide main campus in tropical Darwin, a region with a high proportion of Indigenous peoples [24].

Both Flinders and the Northern Ontario School of Medicine (NOSM) utilise extensive videoconferencing and web-based materials to overcome the otherwise insurmountable inefficiencies of scale, distance and lack of specialist scientific staff in the remote regions. The University of New Mexico (UNM) innovation commenced before the Internet revolution, and utilised specially designed PBL approaches as the enabling learning platform. Each used transformative pedagogies very similar to those used successfully by the LIC clinical educators.

These innovations have demonstrated that students can learn their basic medical sciences in smaller remote communities. However, these examples have limitations. NOSM has large components of medical sciences still delivered in large groups at main campuses. Flinders and UNM only provide the remote opportunity for a small proportion of their total student body. In the clinical education space, following the introduction of LIC community-based approaches in small subcohorts of students in the pioneer schools, new schools are now establishing this approach for all their students [25]. 
Could the same occur for medical science education? And if such scaling-up was successful, could it reduce the requirement for the number of medical schools, with fewer early adopter schools providing education to large numbers of small groups of students crossing traditional geographic boundaries?

Could the entrance examination for these schools be the equivalent of the USMLE Step 1, with students having a choice in how they attained this level of knowledge-through university course work, through private study groups, through personal interrogation of the teaching resources already on the web, etc? Whilst many would assert that the current PBL/ $\mathrm{CBL} / \mathrm{TBL}$ integrated approaches to teaching the basic sciences are the gold standard, the theory of disruptive technologies suggests that it is not always the gold standard that provides what the majority of society's wants or needs. Would such an approach to both basic medical science and clinical training be a cost-effective solution to the global shortage of health professionals, particularly in the developing world [26]?

Could it be that with the climate change of social accountability and changes to patterns of clinical care, the warming waters of the community will significantly remodel the current medical education campus atolls?

\section{Danger! The Three Assertions of the Apocalypse}

Before going any further, however, we must address the apprehension that such considerations are treading on the dangerous ground of 'dumbing down' medical education? It is a commonly expressed concern across western democracies that a two-tiered medical education system has been developing with a lower echelon of community-focused medical schools formed in the last two decades rapidly receding in the tail of the bright star of the tertiary academic medical centre led schools established last century [27].

First let me restate my prejudice-I lead a medical school that is both community oriented and has a substantial base in a tertiary academic medical centre. I don't see the two groups as having to be exclusive. Second, let me suggest that the arguments used by these proponents are misplacing the blame and perhaps not even evidence based....

The first assertion made by those promoting this concern is that medical schools that are more community focused are intentionally placing less emphasis on medical science research.

Yes, the rich are getting richer and the poor poorer in regards to the NIH funding pool. However, is that more a function of the priorities of the NIH than of the capabilities and aspirations of the medical schools that focus on preparing graduates for working in underserved communities? Yes, a study by a group of community clinicians to determine why poor people often also make poor food choices may not compete on 'scientific merit' with a cluster randomised multiinstitutional double-blind cross-over clinical trial of an oncological pharmaceutical isomer that may result in a marginal extended survival of a rare tumour group with a specific genetic variant, but the Quality Adjusted Life Years (QALYs) may be similar-if the study was ever funded. And the options for industry support for the former are likewise less. Compare the chances of gaining funding from Big Food for the first study compared to gaining funding from Big Pharma for the latter.

Track record is perhaps the largest inequity in the system. Track record breeds track record. The rich get richer. All the more inequitable when the majority of funding decisions in national medical science organisations in the USA and Australia are actually made within the error of measurement of the assessment of the scientific proposals by peers within the system.

What would happen to funding from the NIH or NHMRC if track record was taken out of the assessment process for a significant proportion of the project grant schemes, and judgement was rather based on a hurdle of scientific rigor and project feasibility (as assessed by knowledgeable peers) followed by a ranking based on likely societal impact and importance to communities served by the research organisation (as assessed by people inside and outside the system)? The extent to which this has distorted our collective approach was made evident to me when, during a discussion of social accountability of medical schools, a clinician scientist at a very successful medical school, when asked to define the community they were accountable to, responded 'The NIH'!

Furthermore, the community-based schools are wellplaced to address research questions in disease prevention and in the T2 implementation phase of translational research. Unfortunately, despite the promise of equal if not greater QALY returns on research investment, the major funding bodies in Australia and North America disproportionately fund discovery and $\mathrm{T} 1$ curative research, thus discriminating against those community-based schools that are more suited to other equally valid research priorities.

The second assertion in the argument is that communityoriented medical schools place less emphasis on their students understanding the medical sciences and thus being able to utilise advances in medical science in their future careers.

Do primary care physicians in the community need to understand medical science? Absolutely! Take a common primary care condition, diabetes, for example. Advances in the primary care understanding of type-two diabetes include the impact of nutrition, common medications and the human genome on the microbiome, the subsequent disruption of the epithelial function in the bowel wall and resultant endocrine imbalance. Treatment requires, amongst other skills, an understanding of why smart people make poor choices. 
Personalising this to individual patients requires a thorough knowledge of biochemistry, pharmacology, genetics, microbiology, anatomy, and histology-even before you get to the clinical sciences of endocrinology and psychology. Dealing with this complexity at the primary care level almost makes the tertiary care level of balancing insulin, glucose, potassium and $\mathrm{pH}$ levels in ketoacidosis look simple.

Thus, any medical school aiming to produce more community-based physicians working in areas of need has just as strong a mandate for their graduates to understand the medical sciences as a traditional twentieth century Flexnerian school.

However, there is a third assumption inherent in the antitwenty-first century argument-that because students do not learn face to face from highly funded scientists, their knowledge of the medical sciences and ability to use and assess future advances will be less. However, here, there is no evidence presented for this assertion in most iterations of this argument.

Could this be because no evidence exists? There were no data presented to support that students not exposed to highly funded researchers perform more poorly on any of the national tests of medical knowledge, especially if differences in learning opportunity prior to medical school are taken into account. Contrary to this assumption, evidence from a North American community-engaged school I know well, the Northern Ontario School of Medicine, is that their students perform equally well on national examinations as their peers from twentieth-century schools and therefore gain entrance to the speciality of their choice [28].

Where is the evidence that successful researchers make better teachers? Yes, I have some great clinician-scientists who are also great teachers and some highly esteemed basic scientists who love to teach, but these anecdotes do not prove that others cannot enable students to learn just as well. Rather, the recent WHO examination of eLearning by Imperial College London [29] demonstrated that, compared to traditional teaching by traditional twentieth-century faculty, eLearning approaches, able to be implemented by schools without resident research stars, showed at least equivalent outcomes in the vast majority of studies. Certainly the evidence from the clinical education space is that students who learn in technology supported environments with generalist teachers perform equally well as students who learn from specialist clinician-scientists.

Thus, I assert that the very real dichotomy between funding flowing for medical science research in those twentieth-century schools based in academic medical centres and those more twenty-first century schools focused on community-based care is not proof of a lesser valuing for medical science in the latter group, nor evidence for lesser knowledge in the medical sciences by the graduates of these schools. Neither is it a reason to deny the validity of the combined disruptive technologies of local social accountability and the global digital world.

\section{An Uncomfortable Truth?}

If, then, we are not threatening a second-class education, nor undermining the important contribution that medical schools make through research, perhaps this voice should be heard. If we are observing that community-based approaches provide attractive elements to both institutions and society, where does this leave the current medical science academics comfortably engrossed in their work on the university campus island, seemingly impervious to the democratisation of knowledge and the changes to clinical care in the surrounding communities that may threaten its relevance and possibly even its existence?

Medical science education is too important for it to be left to a market-driven solution led by opportunistic entrepreneurs. Those with the expertise and commitment must lead the way.

In this article, I have considered how it may be possible, and possibly necessary, for medical science education to engage outside the island of the campus using the bridges built by clinical educators, and to encourage students to venture into, or remain in, the surrounding waters of the community from the beginning of their courses. We have considered case study evidence for community-based approaches to medical education, theoretical pedagogical frameworks that have emerged, the clear links with blended learning and the democratisation of knowledge, the overstatements by some who are concerned about unintended consequences, and how these principles could be applied to the teaching of medical sciences.

I suggest that if we refuse to either build or use the bridge offered by community-based longitudinal integrated learning approaches and the digital age, then we had better learn to swim in the creeping waters of anachronism. Any scientific assessment would confirm that the climate of medical education is changing; the wonderful islands that served the twentieth-century approaches are desperately resorting to unsustainable landfill-like assertions to pretend their future is secure. The global digital age is more than compatible with local social accountability. But beware being left behind on the university campus atoll. Eventually the sands of history will be submerged by the tide of the future.

\section{References}

1. Worley P, Murray R. Social accountability in medical education-an Australian rural and remote perspective. Medical Teach. 2011;33(8):654-8. 
2. World Health Organization. World Health Assembly Resolution WHA48.8: re-orientating medical education and medical practice for health for al. Geneva: World Health Organization; 1995.

3. The Training for Health Equity Network. THEnet's Social Accountability Evaluation Framework Version 1. Monograph I (1 ed.). The Training for Health Equity Network, 2011.

4. World Federation for Medical Education. Basic Medical Education: WFME Global Standards for Quality Improvement. 2003 Available at http://wfme.org/standards/bme/3-quality-improvement-in-basicmedical-education-english/file (Accessed 29 May 2015)

5. Global Consensus for Social Accountability in Medical Education. Consensus Document 2010 Available at http:// healthsocialaccountability.org/ (Accessed 29 May 2015)

6. Association for Medical Education in Europe. Aspire: the international recognition of excellence in education. Available at http:// www.aspire-to-excellence.org/ (Accessed 29 May 2015)

7. Hirsh D, Worley P. Better learning, better doctors, better community: how transforming clinical education can help repair society. Med Educ. 2013;46(9):826-7.

8. Prideaux D, Worley P, Bligh J. Symbiosis: a new model for clinical education. Med Teach. 2007;4:209-12.

9. Walters L, Greenhill J, Richards J, Ward H, Campbell N, Ash J, et al. Outcomes of longitudinal integrated clinical placements for students, clinicians and society. Med Educ. 2012;46(11):1028-41.

10. Worley P, Martin A, Prideaux D, Woodman R, Worley E, Lowe M. Vocational career paths of graduate entry medical students at Flinders University: a comparison of rural, remote and tertiary tracks. Med J Aust. 2008;188(3):177-78.

11. Walters L, Prideaux D, Worley P, Greenhill J. Demonstrating the value of longitudinal integrated placements to general practice preceptors. Med Educ. 2011;45:455-63.

12. Worley P, Esterman A, Prideaux D. A cohort study of the examination performance of undergraduate medical students learning in community settings. Br Med J. 2004;328:207-9.

13. Hirsh D, Gaufberg E, Ogur B, Cohen P, Krupat E, Cox M, et al. Educational outcomes of the Harvard Medical School-Cambridge integrated clerkship: a way forward for medical education. Acad Med. 2012;87(5):643-50.

14. Mennin SP, Kalishman S, Friedman M, Pathak D, Snyder J. A survey of graduates in practice from the University of New Mexico's conventional and community-oriented, problem-based tracks. Acad Med. 1996;71(10):1079-89.

15. Werner PT, Richards RW, Fogle BJ. Ambulatory family practice experience as the primary and integrating clinical concept in a four-year undergraduate curriculum. J Fam Pract. 1978;7(2):32532.

16. Grimshaw G, Eccles M, Lavis J, Hill S, Squires J. Knowledge translation of research findings. Implement Sci. 2012;7:50
Available at http://www.implementationscience.com/content/7/1/ 50 (Accessed 29 May 2015)

17. Savage G (2012) Digital dawn: open online learning is just beginning. The Conversation. Available at https:/theconversation.com/ digital-dawn-open-online-learning-is-just-beginning-7758 (Accessed 29 May 2015)

18. Colt H, Quadrelli S. Democratization of medical knowledge and technology: brief commentary on implications for medical education. Simul Healthc. 2006;1(4):238-9. Winter.

19. Worley PS, Prideaux D, Strasser R, March R, Worley E. What do medical students actually do on clinical rotations? Med Teach. 2004;26(7):594-8.

20. Osmosis. Available at https://www.osmosis.org/ (Accessed 29 May 2015)

21. West M, Mennin SP, Kaufman A, Galey W. Medical students' attitudes toward basic sciences: influence of a primary care curriculum. Med Educ. 1982;16(4):188-91.

22. Strasser R, Lanphear J. The Northern Ontario School of Medicine: responding to the needs of the people and communities of Northern Ontario. Educ Health. 2008;20:(issue 3) Available from: http:/ www.educationforhealth.net/ (Accessed 29 May 2015)

23. Strasser R, Hogenbirk JC, Minore B, Marsh DC, Berry S, Mccready WG, et al. Transforming health professional education through social accountability: Canada's Northern Ontario School of Medicine. Med Teach. 2013;35(6):490-6.

24. Worley P. Flinders University School of Medicine, Northern Territory, Australia: achieving educational excellence along with a sustainable workforce. Med Rev. 2008;10(4):30-4.

25. Couper I, Worley PS, Strasser R. Rural longitudinal integrated clerkships: lessons from two programs on different continents. Rural and Remote Health 11 (online), 2011: 1665. Available from: http://www.rrh.org.au (Accessed 29 May 2015)

26. Brazeau NK, Potts MJ, Hickner JM. The Upper Peninsula Program, a successful model for increasing primary care physicians in rural areas. Fam Med. 1990;22(5):350-5.

27. Feldman A, Runge M, Garcia J, A. American medical education at a crossroads. Sci Transl Med. 2015; Vol 7(Issue 285):p. 285fs 17 Available at http://stm.sciencemag.org/content/7/285/285fs17.full? sid=26117f31-6048-484c-9674-0f6b86517265 (Accessed 29 May 2015)

28. Larkin K. NOSM's class of 2012 matches $100 \%$ to residency programs. 2012 Available at http://www.nosm.ca/about us/ media_room/media_releases/media_release.aspx?id $=14866$ (Accessed 29 May 2015)

29. Al-Shorbaji N, Atun R, Car J, Majeed A, Wheeler E. eLearning for undergraduate health professional education: a systematic review informing a radical transformation of health workforce development. 2015 WHO: Geneva 